\title{
Presidential Address to the American Society for Clinical Investigation, San Diego, California, 6 May, 1995 Values and Value: The Survival of Biomedical Research
}

\author{
Richard D. Klausner \\ Cell Biology and Metabolism Branch, National Institute of Child Health and Human Development, National Institutes of Health, \\ Bethesda, Maryland 20892-5430
}

For almost $50 \mathrm{yr}$ the federal government has been committed to building and maintaining the capacity of the university-based biomedical research system. The system of peer-reviewed research grant funding to universities has produced the most successful health research enterprise in the world. The philosophy and vision of this enterprise was articulated by Vanevar Bush in his classic prescription for the federal role in science called Science: The Endless Frontier. In this document, he provided not only recommendations for structures but more importantly, a vision of the proper role of government in what was accepted as a noble and valued societal effort.

Over the past 15 yr we have come to expect an annual struggle for funds; we've become used to the arguments that pit limited resources against expanding opportunities and used to fights over how much the NIH budget should increase and how many grants will be funded. Today, we face the same issues but the context has changed. The political discourse that underlies our enterprise has undergone a transformation in Washington. Whether it represents a temporary aberration in a 50-yr experience or a real sea change, we cannot tell. The issues raised by this political transformation, however, are so fundamental, I felt I could not ignore them in addressing these clinical research societies.

Even though many individuals responsible for funding this system remain committed to it, we find ourselves in an environment where some of the most fundamental assumptions about federal research funding and of the very value of biomedical research are being questioned.

We are confronted with three challenges about underlying values and that is what I want to address:

1. How noble is the scientific effort-are researchers "just another interest group" drinking at the public trough?

2. Just what is the value of innovation in medicine? Innovation is now being challenged as one of the culprits in escalating health costs.

3 . Is the role of the federal government in carrying out research appropriate? Should the federal government be responsible for maintaining the physical and human infrastructure of our academic health centers and our public and private biomedical research centers?

The first challenge we face is a climate in which antiscience

Address correspondence to Richard D. Klausner, M.D., Cell Biology \& Metabolism Branch, NICHD/NIH, 18 Library Drive, MSC 5430, Building 18T, Room 101, Bethesda, MD 20892-5430. Phone: 301-496-6368; FAX: 301-402-0078.

Received for publication 13 June 1995.

The Journal of Clinical Investigation, Inc.

Volume 96, September 1995, 1181-1183 views prevail. Science seems to have fallen from its pedestal in the public eye, and we must ask why? In the nineteenth century, the scientific enterprise offered the great promise of progress. The scientist was heroic, fighting ancient imprisoning superstitions and questioning authority. Science was supposed to improve society, and in inumerable ways it has. But, it has also been identified with some of the horrors of the twentieth century, from the poison gas of World War I to the age of nuclear terror.

There is no question but that science has profoundly transformed our society. However, scientists' understanding of science and the public's understanding of science differ profoundly and there is an enormous gulf between the knowledge about the world accepted by scientists and what the public either knows or believes to be true. As we approach the end of the twentieth century, polls show that the majority of Americans believe in spontaneous generation and question the germ theory of disease and evolution. This extends to graduates from some of our most prestigious universities, where studies have suggested that $30-40 \%$ of students do not know that the earth revolves around the sun once a year, and the vast majority cannot explain why there are seasons. With the twenty-first century approaching, there is an extraordinary interest in the supernatural; television shows about this greatly outnumber those about science. In contrast to the beginning of this century, scientists and their institutions are viewed by many with suspicion. Some believe we are withholding cures for diseases and many believe that we ignore cures that we see as coming from outside of our formal institutions. Scientists as authorities have failed to live up to unrealistic public expectations and, for many, have failed to live up to the promises that the public has wanted to hear and that we have occasionally unwisely given.

The public seems mistrustful of scientific experts who argue and disagree and who change their minds about diet and therapy, about risks and dangers. While we know that the process of scientific discourse is necessary to progress, when presented to a public woefully illiterate about science, disagreement among " "experts" results in surprise, disappointment, and some disillusionment.

Finally, there is an amazing social change in our culture in which expertise is equated with elitism and the idea of dispassionate professionalism has been tossed aside and replaced with the assumption that expertise means corrupt self-interest. This last point, I believe, underlies, in part, the term limits movement and the myth of political salvation through the citizen politician, a rejection of the dreaded and mistrusted "professional."

The second difficult issue confronting our community is doubt about the value of medical innovation. This has come from the correlation and, in many cases, the actual connections between innovations in medicine and rising costs - more about this in a few minutes. 
Finally, questions about the proper federal role in research are driven by the federal budget crunch and are buttressed by the conservative political viewpoint concerning the limited role of the federal government, or any government, versus the role of industry and the free market.

So what do we do with these three challenges? There is no single answer just as there is no single cause. However, we cannot do nothing. The health of our extraordinary enterprise is truly at stake. I don't need to review the data on funding rates, on the dramatic fall in the number of young applicants for NIH grants, on the increasing difficulty of finding academic research jobs, and the growing demoralization of young researchers and physician scientists. We are not trained to be political activists. However, it is important that we articulate the fundamental value to society of what we do and respond to the challenges of antiscience attitudes, skepticism about medical innovation, and questions about the role of the federal government. We must participate actively in the crucial debates that will define the public support that allows us to do what we do.

My responses to these three issues are the following. First, there is a desperate need to improve the education of the public in and about science. Second, we need to articulate the value of innovation in medicine as the only route to ultimately reducing the cost of illness without abandoning the value that our society places on healthy lives. And third, we need to articulate the unique and irreplaceable role of government as the agent of the peoples' will to prevent and cure disease and as the only institution capable of supporting the core of the biomedical research that these goals demand.

There is a national movement to reform science education in this country. For the first time, we have national standards that describe what all students should know and be able to do in the natural sciences after $13 \mathrm{yr}$ of school. The production of these national standards, a project which I chaired at the National Academy of the Sciences, is only one step toward a more scientifically literate population. While I do not believe that to know us is to love us, I do believe that everyone will benefit from an educational system which truly exposes all students to the joy of science and discovery and gives them some understanding of the natural world and their own bodies. Imagine an educational system that produces congressmen, congress women, governors, and business leaders who are scientifically literate. The biomedical research enterprise depends upon public support and upon the support of elected officials. The public needs to have some understanding of what science is and what it isn't, of the nature of science as a way of inquiry replete with its arguments and evolving and, sometimes, revolving conclusions. The public needs to have a sense of numbers and of probability to begin to understand risk, a sense of the complexity of the natural world to appreciate how hard it is to reach specific goals. Also, the public needs to see science as a human pursuit, practiced by real people, to avoid the shock and disappointment of finding out that science is neither as angelic nor as devilish as Hollywood might portray it. Beyond the formal educational system, we biomedical scientists need to be public speakers. We have marvelous stories to tell about issues that people deeply care about. These stories are our best public relations. They must be told without hype or false promises. We, and our institutions, need to guard against hype and false promises to prevent the skepticism and antagonism that broken promises produce. The promise made in 1983 that a vaccine for AIDS would take $2 \mathrm{yr}$ did enormous harm. Many of us have a vision of a more scientifically literate society for many reasons. For us at this meeting, I believe that enhanced scientific literacy is going to be essential if we are to continue to expect the public and elected officials to support our enterprise.

What about innovation in research and its effects on healthcare costs?

Ultimately, innovation is the only way that the cost of illness and disability and economic loss from premature death can be decreased. Disease will not disappear. Our society will continue to value health and life and to believe that cheap death and unanswered human suffering are simply not options. The arguments for the economic benefits of innovation have been made eloquently by a number of members of our community over the past year, including my colleague Marc Kirschner. They have pointed out some of the problems in the accounting system used to evaluate costs and benefits in the healthcare system. For innovations in medicine that come from research, we fail to amortize our expenditures over the continued savings derived from diseases and disabilities once they are prevented or cured. When a disease such as polio disappears, the costs that would have been incurred leave our ledgers. We must continue to remind the public of the savings that have accrued from innovations. These include vaccines that prevent tremendously expensive diseases including polio, tetanus, measles, hepatitis, and hemophilus influenza type B. The last alone has been estimated to save up to $\$ 400$ million a year. The purely economic benefits of the future development of successful vaccines for TB, HIV, HPV, and Helicobacter, to name just a few, would be enormous. But we don't yet have these and we will never have these without fundamental innovations that require investment - the type of investment that is financially repaid many times over.

Effective therapies such as antidepressants, lithium, antihypertensives, potassium citrate for kidney stone prevention, and others all have produced enormous savings in health costs. Other breakthroughs such as neonatal screening for hypothyroidism, therapy for $\mathrm{Rh}$ incompatibility, and fluoridation of the water supply, to name but a few, have saved billions of dollars.

Yet, medical costs have risen over the time that we have introduced innovative technologies. Must these two be linked?

There are lessons to be learned from the attacks on innovation that have accompanied the recent national debates on healthcare. Innovation needs to be measured in terms of both benefits and costs. Incentives must be in place to demand innovations that produce real benefit and are cost reducing. The lack of incentives for cost containment can allow questionable innovations to drive up costs. Hopefully, we are emerging from a system whose incentives really did allow new technologies to drive the practice of medicine, independent of data on value or outcome or cost or benefit. Insurance reimbursement practices, the lack of incentives for efficiency coupled to effectiveness and conflicts of interest, have all come under scrutiny and are changing. As we build a system with new incentives aimed at cost reductions, we must be sure that these are incentives for real benefits in improved health and that they support, rather than inhibit, innovation. Innovations in prevention and innovations in treatment demand both basic and clinical research and a close and intellectually meaningful interaction between these two aspects of our enterprise. They therefore must be seen as necessary investments and not as expensive indulgences!

This brings me to my last point, the role of the government. 
One can ask whether in our zeal to argue for the economic benefits of biomedical research, will we not play into the hands of those that ask, "If this is so cost-effective, so potentially profitable, why isn't it fully supported by industry, by healthcare deliverers, insurance companies, pharmaceutical, and biotech companies?" The answer lies in a fundamental conflict between the nature of industry and the nature of biomedical research. Industry actually supports the bulk of what is classified as research in this country. But the Commerce Department tells us that the average life span of industrial research is only $3 \mathrm{yr}$ and evidence suggests that market pressures will only make this worse. Biomedical research must be a long-term commitment for many reasons. First, it is fundamentally unpredictable how long it will take to reach a particular goal. Second, specific planning is very limited as the unexpected course of scientific inquiry leads to unexpected applications, answers, and benefits. Third, it is rare for the returns on a single scientific project to lead to financial payoffs in the short run, certainly not in $3 \mathrm{yr}$ ! Fourth, disease itself is a moving target and requires a large and flexible infrastructure of response. Finally, effective research requires people who are trained, institutions capable of that training, technological advances, and a constantly improving physical infrastructure. This infrastructure, both physical and human, has often and aptly been compared with the interstate highway system - an investment that no single trucking firm could have made - one whose benefit to society is long-lasting and enormous - a clear example of providing for the public good that is the true and rightful and expected role of government.

So it is with the biomedical research enterprise. It is an investment that the whole society benefits from, whose efficacy emerges from the aggregate and over a long, or at least unpredictable, time scale. It is providing for the public good in the most profound and basic way, and the health it seeks to assure is a prerequisite for the life, liberty, and pursuit of happiness which we expect our government to support.

So what can we do? In short, we must be engaged. We must be knowledgeable about the benefits of science and be able to describe them without hype or false hope. We must use our intellectual and institutional resources to participate in improving scientific literacy without sacrificing our core missions. We must try to mobilize those who should be allies into a true alliance. These allies include the entire health care delivery system, business, voluntary health organizations, and others concerned with the social welfare in our society. We need to return the agenda of discourse back to the very value of biomedical research. There is no definitive argument for a given level of public funding for biomedical research, no absolute number of grants or clinical trials or trainees. Ultimately, the extent to which we are supported will be a direct reflection of the value our culture places on the process, the promise, and the progress of science. 